\section{Effects of Cluster Size and Shoot Type on Characteristics of Pecan Nuts}

\author{
Charles T. Rohla, ${ }^{1}$ Michael W. Smith, ${ }^{2}$ and Niels O. Maness ${ }^{3}$ \\ Department of Horticulture and Landscape Architecture, Oklahoma State \\ University, Stillwater, OK 74078
}

Additional index words. Carya illinoinensis, fruit, nut, fruit number, kernel development, nut size, kernel percentage, return bloom, flowering, alternate bearing, irregular bearing

\begin{abstract}
Whole fruit clusters of 'Pawnee' pecan [Carya illinoinensis (Wang.) C. Koch.] were collected from three shoot types: terminal and lateral shoots without a secondary growth flush and shoots that had an early-season secondary growth flush. Fruit per cluster were counted and nuts were individually harvested, weighed, shelled and graded. Bloom the following year was determined for the same shoots where clusters were collected. Wafers (cotyledons that failed to develop) were not associated with cluster size or shoot type. When wafers were included in the data, nut weight, kernel percentage and return bloom were not affected by cluster size or shoot type. However, when wafers were excluded from the data there were significant relationships of cluster size and shoot type with the dependent variables. Cluster size on lateral shoots was negatively related to nut weight and kernel percentage. Cluster size on terminal shoots without a secondary growth flush was inversely related to kernel percentage, but not related to nut weight. When shoots had a secondary growth flush, cluster size was not related to kernel percentage or nut weight. There was a positive linear relationship between cluster size and total kernel weight for the three shoot types. Return bloom of terminal shoots without a secondary growth flush was negatively related to cluster size, but cluster size did not affect return bloom of the other shoot types. The number of shoots that developed the following year was positively related to cluster size for terminal and lateral shoots, but not for shoots with a secondary growth flush. Shoots with a secondary growth flush produced substantially more shoots with larger fruit clusters the next year than the other shoot types.
\end{abstract}

Pecan fruit production is irregular, typified by high production 1 year followed by one or more years of low production (Sparks, 1986). This may best be characterized as alternate bearing with irregular symmetry. Alternate bearing is typically associated with a lack of return bloom rather than flower or fruit abortion. Crane et al. (1934) reported a leaf to fruit ratio of 8 to 10 leaves per fruit was required for development of good quality nuts. They also suggested that cultivars with a large cluster size might have a lower percentage of return bloom than those with a smaller cluster size. Reid (1986) speculated that cultivars with large fruit clusters typically had poorer fruit quality than cultivars with small clusters. It is often suggested by scientists working with pecans that quality and consistent production of 'Desirable' can be attributed to its large fruit drop, resulting in one or two fruit per cluster by the dough stage. This may be related to the fruit carbohydrate demand or growth regulators that inhibitflower induction proportionately to the fruit or cluster size.

Return bloom of fruiting shoots is less than that of same season vegetative shoots (Malstrom and McMeans, 1982; Smith et al.,

Received for publication 3 Dec. 2004. Accepted for publication 19 Feb. 2005. Approved for publication by the Oklahoma Agricultural Experiment Station. Funded by the OklahomaAgricultural ExperimentStation and the USDA Crop Germplasm Committee.

${ }^{1}$ Graduate student.

${ }^{2}$ Regents professor and corresponding author, e-mail mike.smith@okstate.edu.

${ }^{3}$ Professor. tober. Nitrogen was surface-applied in March at $112 \mathrm{~kg} \cdot \mathrm{ha}^{-1} \mathrm{~N}$ from urea plus $142 \mathrm{~kg} \cdot \mathrm{ha}^{-1} \mathrm{~N}$ was applied from $\mathrm{NO}_{3}$-contaminated irrigation water. Five foliar $\mathrm{Zn}$ applications were made between budbreak and July at $2.4 \mathrm{~kg} \cdot \mathrm{ha}^{-1} \mathrm{Zn}$ from $36 \% \mathrm{ZnSO}_{4}$. Pest management followed extension recommendations for a commercial orchard (von Broembsen et al., 1997).

Whole fruit clusters from thirty shoots each of three bearing shoot types on each tree were randomly selected, tagged to monitor return bloom and then individually harvested at shuck split. The three bearing shoot types were 1) shoots in the terminal position without a secondary growth flush, 2) shoots in the lateral position without a secondary growth flush, and 3 ) shoots, primarily in the terminal position, with a secondary growth flush. The number of fruit per cluster (cluster size) was recorded from each shoot, and then nuts were harvested at shuck split, dried, individually weighed, and shelled. In total, 270 fruit clusters were harvested ranging in size from 1 to 11 fruit per cluster for a total of nearly 1300 nuts. The following spring, total current season shoots per 1-year-old branch and the percentage of 1-year-old branches that produced one or more shoots with pistillate flowers was determined. Various models were fitted to the data and the most appropriate model was chosen for each variable.

\section{Results and Discussion}

Cluster size was unrelated to nut weight, kernel percentage or return bloom for any shoot type when nuts with undeveloped cotyledons (wafers, testa develops but little, if any, carbohydrate and oil deposition) were retained in the data(data not shown). Percentage of wafers was not associated with cluster size for any shoot type (Fig. 1). Wafers were excluded from the data, and cluster size was recalculated along with weight/nut, kernel percentage and total kernel weight/shoot. The relationship of cluster size for each shoot type was then determined for the dependent variables.

The most frequent occurring cluster size on terminal shoots was $\leq 3$ fruit per cluster (Fig. 1). On shoots with a secondary growth flush 5 fruit per cluster occurred more frequently than other sizes. Shoot vigor is positively related to the cluster size formed the next year (Dodge and Crane, 1933). If shoots with a secondary growth flush were more vigorous the previous year than the terminal shoots without a secondary growth flush, then cluster size was probably initially larger on shoots with a secondary growth flush. Alternatively, fruit drop may have been less on the vigorous shoots with a secondary growth flush. Lateral shoots were intermediate in cluster size with 3 to 4 fruit per cluster dominating.

Cluster size was not related to average nut weight on terminal shoots and shoots with a secondary growth flush (Fig. 2). However, on lateral shoots average nut weight decreased about $18 \%$ as cluster size increased from 1 to 8 fruit per cluster. These data suggest that nuts are more likely to be smaller on lateral shoots than on terminal shoots or on shoots 
with a secondary growth flush as cluster size increases. The average weight per nut, pooled over cluster sizes, was $8.2,8.3$, and $8.0 \mathrm{~g}$ for terminal shoots, shoots with a secondary growth flush and lateral shoots, respectively. Thus nuts from lateral shoots averaged about 3\% smaller than those on terminal shoots or shoots with a secondary growth flush. The leaves on a shoot primarily support fruit development on that shoot (Davis and Sparks, 1974). Few carbohydrates are transported from surrounding shoots to support fruit development; therefore, shoots with more leaves could support larger fruit clusters. Terminal shoots and shoots with a secondary growth flush tend to be longer with more leaves than lateral shoots, so nut weight was only affected by cluster size on the shorter lateral shoots. Additionally, because of their location on the branch more shading of lateral shoots occurs, reducing photosynthesis and consequently nut weight.

Kernel percentage was negatively related to cluster size on terminal and lateral shoots, but not on shoots with a secondary growth flush (Fig. 3). On terminal shoots, kernel percentage was reduced about $5 \%$ (from $56.9 \%$ to $53.8 \%$ ) and about $6 \%$ (from $56.4 \%$ to $52.8 \%$ ) on lateral shoots as cluster size increased from 1 to 8 fruit per cluster. Kernel percentage of shoots with a secondary growth flush averaged $55.4 \%$.

Total kernel weight per shoot increased linearly as cluster size increased (Fig. 4). More fruit in a cluster should increase kernel weight per shoot. The linear increase in total kernel weight with cluster size for each shoot type suggests that even at 8 or 9 fruit/cluster, the shoot had not reached its maximum carrying capacity. A curved relationship would suggest that shoots were approaching their maximum fruit carrying capacity with the larger fruit cluster sizes. A reduction in kernel percentage with greater cluster size (Fig. 3) suggests that terminal and lateral shoots were nearer their carrying capacity than indicated by total kernel weight. Alternatively, shell weight may be increased disproportionately to kernel weight when cluster size was increased, and this was reflected in kernel percentage on terminal and lateral shoots.

Return bloom was negatively related to cluster size on terminal shoots, although the correlation was weak, but not on the other shoot types (Fig. 5). This suggests that return bloom on lateral shoots and shoots with a secondary growth flush was unaffected by cluster sizes from 1 fruit to 8 fruit per cluster. However, on terminal shoots return bloom was $60 \%$ with 1 fruit/cluster and reduced to $17 \%$ fruiting with 8 fruit/cluster. Return bloom, averaged over all cluster sizes, was $70 \%$ on shoots with a secondary growth flush, $33 \%$ for lateral shoots, and $43 \%$ terminal shoots.

Total shoots per 1-year-old branch increased linearly as cluster size increased on terminal and lateral shoots, but not on shoots with a secondary growth flush (Fig. 6). Values for total shoots per 1-year-old branch, averaged over all cluster sizes, were 4.2 on shoots with a secondary growth flush, 2.4 for lateral shoots, and 2.4 for terminal shoots. Cluster size was not related to total fruits per 1 -year-old branch produced the following year for any shoot type (data not shown). However, shoots with a secondary growth flush produced over twice as many fruits per branch as the other shoot types. The total fruit per branch produced the following year was 5.7 on shoots with a secondary growth flush, 1.7 for lateral shoots, and 2.4 for terminal shoots.

These data suggest that a large cluster size on lateral shoots negatively impacts nut weight and kernel percentage. Similarly, kernel percentage was reduced by large fruit clusters on terminal shoots. Shoots with a secondary growth flush supported up to nine fruit per cluster with no effect on nut size or kernel percentage. Additionally, shoots with a secondary growth flush gave rise to more shoots with larger fruit clusters the next year than other bearing shoot types. It is evident from these data that vigorous trees with substantial amounts of shoots with a secondary growth flush are more likely to produce fruit consistently. Also, vigorous shoots can carry larger fruit clusters than less vigorous shoots with little, if any, effect on quality. It must be pointed out that the secondary growth flushes in this study began in June, early in the growing season. Thus the additional leaf surface area was present as the fruit developed. Early-season growth flushes result in a net carbohydrate gain (Andersen and Brodbeck, 1988), thus there is a positive impact on developing fruit. Pecan trees occasionally make a late-season growth flush in September or early October. Trees producing late-season growth flushes are typically nonirrigated trees that have experienced summer drought followed by abundant September rainfall. Our observations suggest that a secondary growth flush in September or October is detrimental to kernel quality since the rapid shoot growth competes directly with developing cotyledons. Late-summer growth flushes consume more

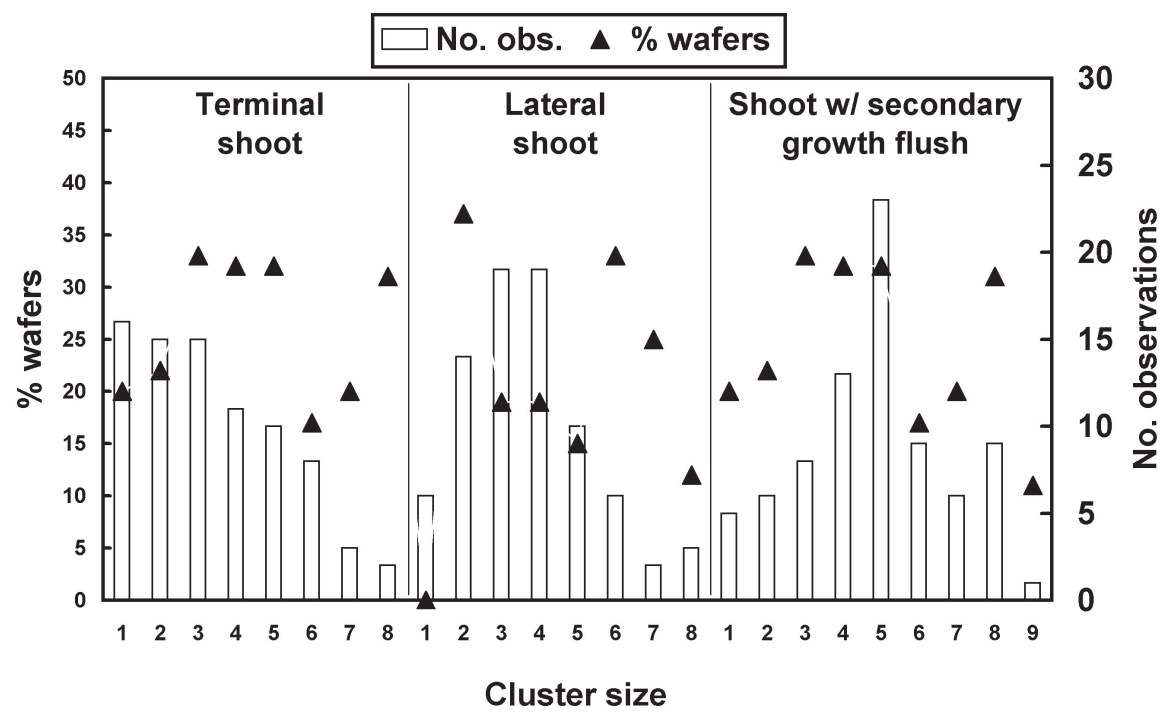

Fig 1. The number of observations for each shoot type and cluster size (vertical bars), and the relationship of cluster size and shoot type with incompletely developed cotyledons (wafers) (scatter diagram).

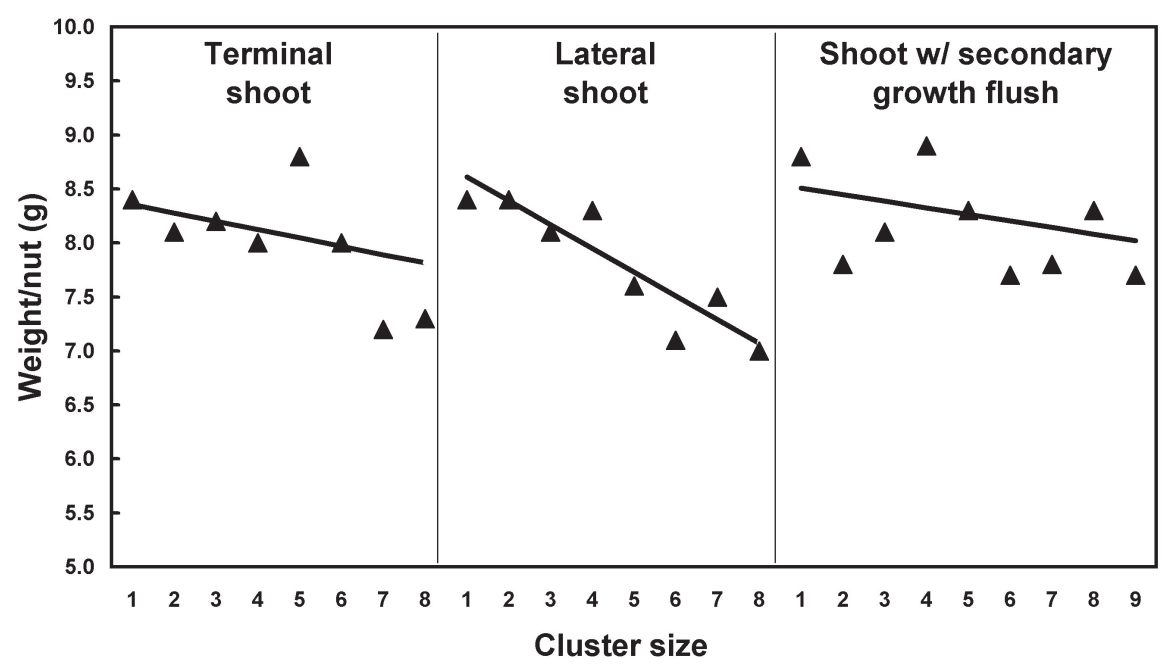

Fig 2. Relationship of cluster size and shoot type with weight per nut the same year. Triangles are the average of 3 to 37 observations for each cluster size and shoot type. Terminal: weight $/ \mathrm{nut}(\mathrm{g})=8.4$ -0.077 (cluster size), $r^{2}=0.178, \mathrm{df}=79, p>0.2374$; lateral: weight $/$ nut $(\mathrm{g})=8.8-0.221$ (cluster size), $r^{2}=0.13, \mathrm{df}=78, p>0.0010$; secondary growth flush: weight $/$ nut $(\mathrm{g})=8.6-0.061$ (cluster size), $r^{2}=0.02, \mathrm{df}=79, p>0.2735$. 
carbohydrates during development than they produce (Andersen and Brodbeck, 1988). We expect early-season and late-season growth flushes to affect nut quality and return bloom differently. An early-season growth flush was advantageous for current season nut quality and subsequent return bloom. We hypothesize that a late-season growth flush negatively impacts nut quality.

The weak relationship between cluster size and return bloom for terminal shoots without a secondary growth flush and the nonsignificant relationships for lateral shoots and shoots with a secondary growth flush was surprising. It has been well documented that current-year fruit suppresses return bloom compared to current-year vegetative shoots (Malstrom and McMeans, 1982; Smith et al., 1986). These data suggest that return bloom suppression was only slightly enhanced or not affected as cluster size increased. Thus a small cluster size does not necessarily increase the likelihood of improved return bloom, as has been speculated (Crane et al., 1934; Reid, 1986).

Carbohydrate reserves have been implicated in pecan alternate bearing, i.e., large crops deplete carbohydrate reserves resulting in small crops the following year (Smith and Waugh, 1938; Sparks, 1974; Sparks and Brack, 1972; Wood, 1989, 1995; Wood et al., 1987; Worley, 1979a, 1979b). Since larger clusters require more carbohydrates to develop than small clusters, the large clusters should deplete carbohydrates and cause greater return bloom suppression. However, the relationship between cluster size and return bloom was weak or not significant, suggesting that carbohydrate supply on an individual shoot basis was not a

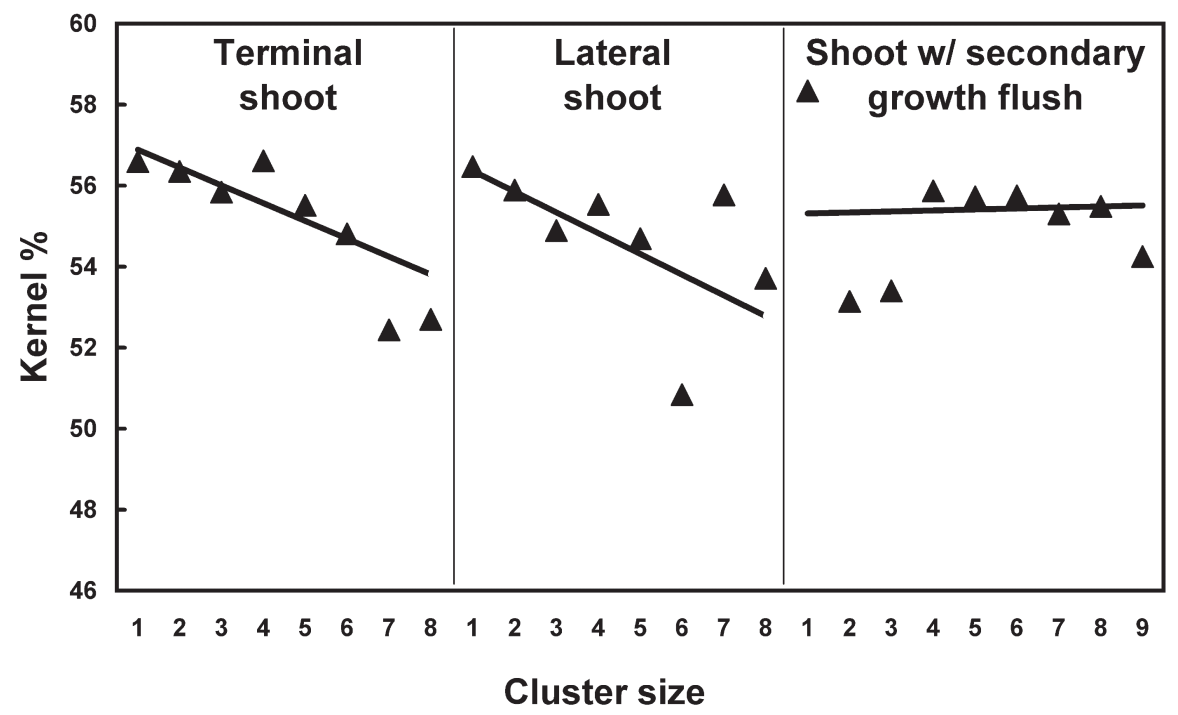

Fig 3. Relationship of cluster size and shoot type with kernel percent the same year. Triangles are the average of 3 to 37 observations for each cluster size and shoot type. Terminal: percent kernel $=57.33$ -0.440 (cluster size), $r^{2}=0.08, \mathrm{df}=79, p>0.0105$; lateral: percent kernel $=56.87-0.512$ (cluster size), $r^{2}=0.06, \mathrm{df}=78, \mathrm{p}>0.0237$; secondary growth flush: percent kernel $=55.29+0.025$ (cluster size), $r^{2}=0.01, \mathrm{df}=79, p>0.8524$.

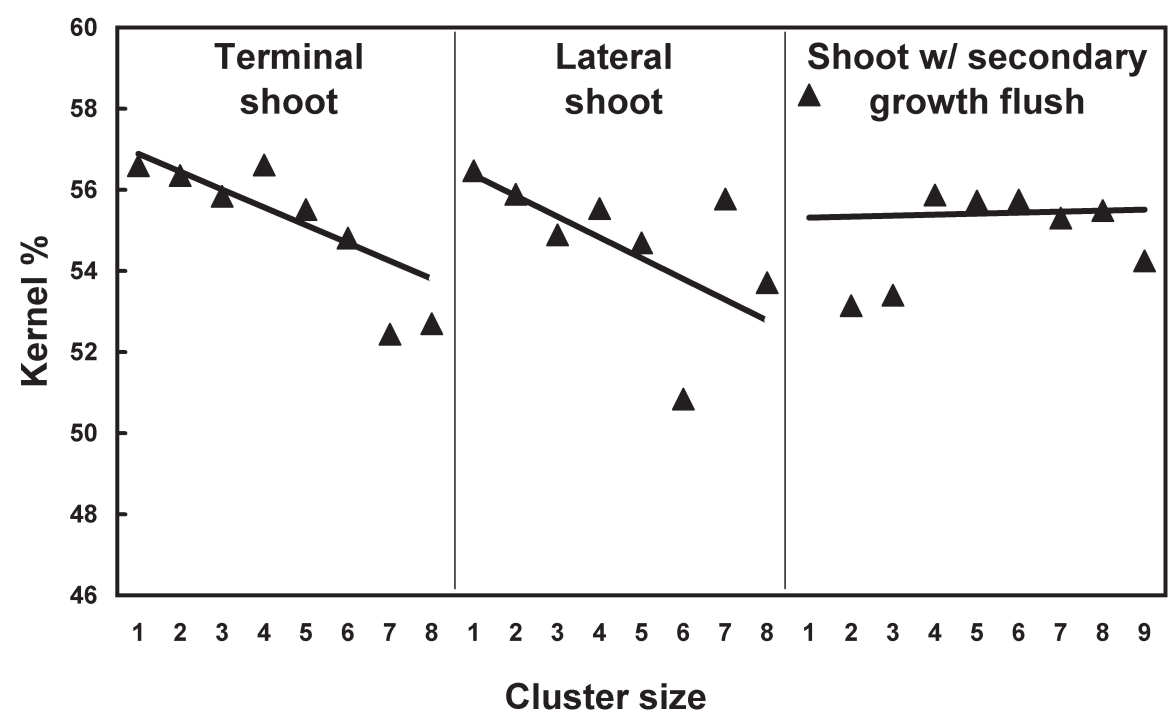

Fig 4. Relationship of cluster size and shoot type with total kernel weight/shoot the same year. Triangles are the average of 3 to 37 observations for each cluster size and shoot type. Terminal: total kernel weight $(\mathrm{g})=1.1+4.17$ (cluster size) $, r^{2}=0.88, \mathrm{df}=79, p>0.0001$; lateral: total kernel weight $(\mathrm{g})=$ $2.5+3.64$ (cluster size), $r^{2}=0.84, \mathrm{df}=78, p>0.0001$; secondary growth flush: total kernel weight $(\mathrm{g})$ $=0.68+4.43$ (cluster size), $r^{2}=0.90, \mathrm{df}=79, p>0.0001$.

major factor controlling return bloom. In fact, another study found that the total non-structural carbohydrates in the fall, during dormancy and at budbreak of current-season fruiting shoots were greater or equal to vegetative shoots, yet return bloom of vegetative shoots was significantly greater than fruiting shoots (Smith et al., 1986). Thus carbohydrates appear to play a minor role in regulating return bloom of individual shoots.

Agrowth regulator(s) produced by the fruit may be involved in determining return bloom (Smith et al., 1986), but in this study return bloom suppression by fruit in the cluster was not additive. The lack of an additive effect by fruit in a cluster might be associated with larger clusters occurring on more vigorous shoots, thus mitigating the effects of cluster size on return bloom. A more likely scenario is that a single fruit produces sufficient growth regulators to affect return bloom with little additional impact from more fruit in the cluster.

Vigorous shoots clearly have a greater return bloom than less vigorous shoots. In this study, return bloom of shoots with a secondary growth flush was $70 \%$ compared to $43 \%$ and $33 \%$ for terminal and lateral shoots, respectively. Longer shoots have more leaves that may produce more growth regulators that promote subsequent year flowering. Longer shoots with more leaves produce more carbohydrates, but the carbohydrate supply does not appear to be the major limiting factor for return bloom of an individual shoot. Carbohydrate reserves appear to be important in determining tree survival (Wood, 2001) and the ability to flower (Smith et al., 1986) rather than controlling flower induction on individual shoots.

\section{Literature Cited}

Andersen, P.C. and B.V. Brodbeck. 1988. Net CO2 assimilation and plant water relations characteristics of pecan growth flushes. J. Amer. Soc. Hort. Sci. 113:444-450.

Crane, H.L., M.B. Hardy, N.H. Loomis, and F.N. Dodge. 1934. Effect of nut thinning on size, degree of filling, and annual yields of pecans. Proc. Amer. Soc. Hort. Sci. 32:29-32.

Davis, J.T. and D. Sparks. 1974. Assimilation and translocation patterns of carbon-14 in the shoot of fruiting pecan trees, Carya illinoensis Koch. J. Amer. Soc. Hort. Sci. 99:468-480.

Dodge, F.H. and H.L. Crane. 1933. Time and duration of growth of several types of shoots in relation to fruiting performance of the pecan. Nat. Pecan Assoc. Bul. 32:64-65.

Malstrom, H.L. and J.L. McMeans. 1982. Shoot length and previous fruiting affect subsequent growth and nut production of 'Moneymaker' pecan. HortScience 17:970-972.

Reid, W. 1986. Reasons for poor kernel filling. Annu. Rpt. Northern Nut Growers' Assn. 77:37-38.

Reid, W., S.M. Huslig, M.W. Smith, N.O. Maness, and J.L. Whitworth. 1993. Fruit-removal time influences return bloom in pecan. HortScience 28:800-802.

Smith, C.L. and J.G. Waugh. 1938. Seasonal variations in the carbohydrate and nitrogen content of roots of bearing pecan trees. J. Agr. Res. $57: 449-460$

Smith, M.W. and J.C. Gallott. 1990. Mechanical thinning of pecan fruit. HortScience 25:414-416.

Smith, M.W., R.W. McNew, P.L. Ager, and B.C. Cotten. 1986. Seasonal changes in the carbo- 


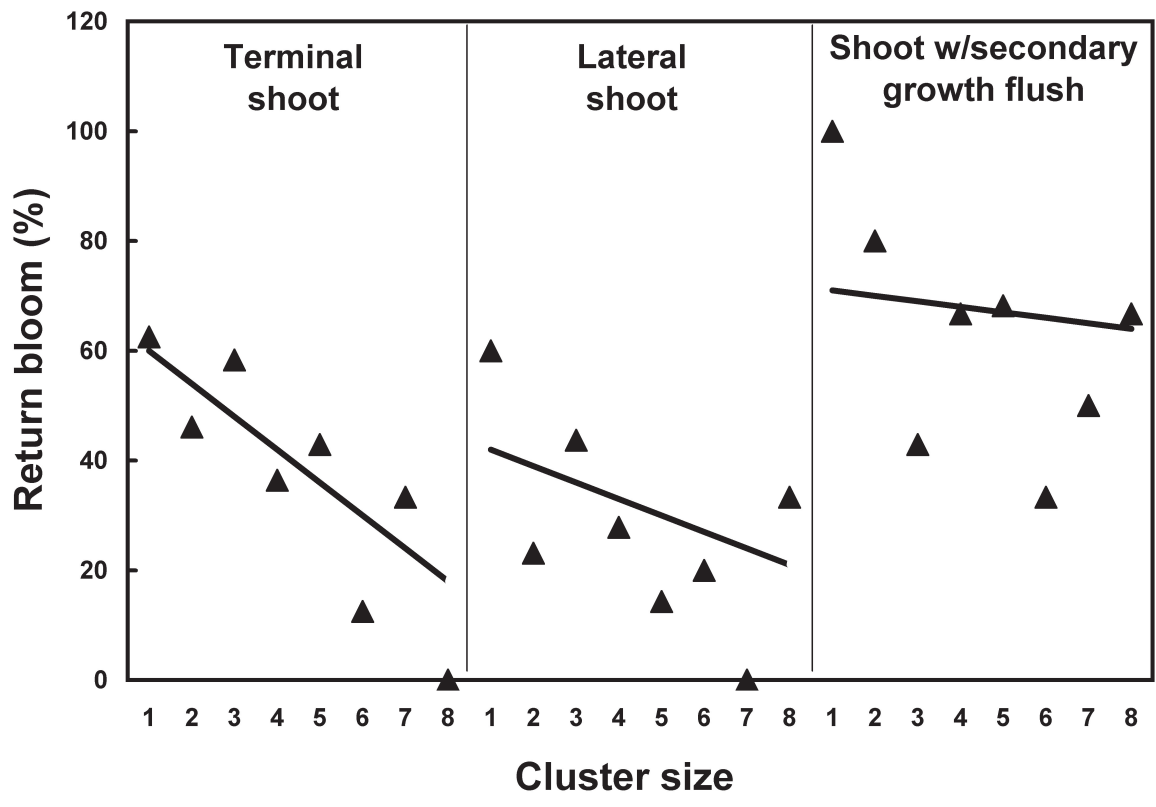

Fig 5. Relationship of cluster size with percentage of 1-year-old branches producing shoots with pistillate flowers the subsequent year. Triangles are the average of 3 to 37 observations for each cluster size and shoot type. Terminal: percent return bloom $=66.0-6.08$ (cluster size), $r^{2}=0.62, \mathrm{df}=6, p>0.0366$; lateral: percent return bloom $=45.3-3.27$ (cluster size), $r^{2}=0.25, \mathrm{df}=6, p>0.2507$; secondary growth flush: percent return bloom $=72.4-0.98$ (cluster size), $r^{2}=0.01, \mathrm{df}=8, p>0.7672$.

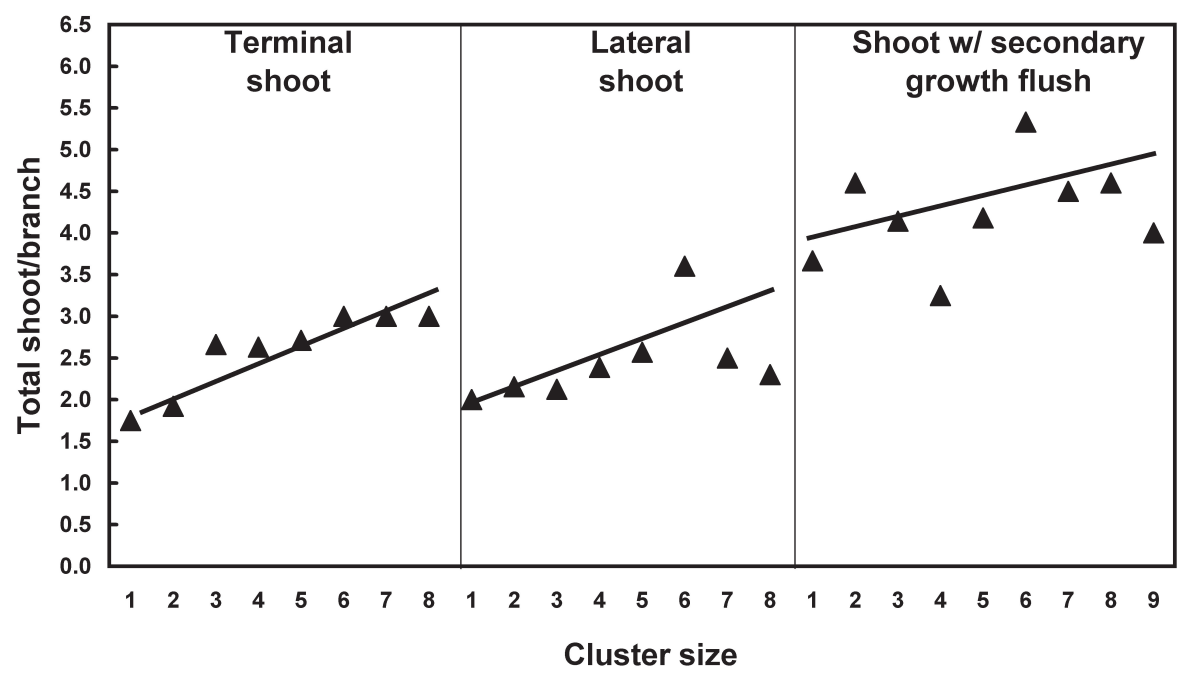

Fig 6. Relationship of cluster size and shoot type with the total shoots produced per 1-year-old branch the subsequent year. Triangles are the average of 3 to 37 observations for each cluster size and shoot type. Terminal: shoots/branch $=1.64+0.22$ (cluster size) $r^{2}=0.27, \mathrm{df}=71, p>0.0001$; lateral: shoots/branch $=1.83+0.14$ (cluster size) $, r^{2}=0.08, \mathrm{df}=68, p>0.0154 ;$ secondary growth flush: shoots/branch $=3.57$ +0.134 (cluster size), $r^{2}=0.03, \mathrm{df}=73, p>0.1141$. hydrate concentration in pecan shoots and their relationship to flowering. J. Amer. Soc. Hort. Sci. 111:558-561.

Smith, M.W., W. Reid, B. Carroll, and B. Cheary. 1993. Mechanical fruit thinning influences fruit quality, yield, return fruit set and cold injury of pecan. HortScience 28:1081-1084.

Sparks, D. 1974. The alternate bearing problem in pecans. N. Nut Growers' Assn. 47:80-85.

Sparks, D. 1986. Pecan, p. 323-339. In: S.P. Monselise (ed.). Handbook of fruit set and development. CRC, Boca Raton, Fla.

Sparks, D. and C.E. Brack. 1972. Return bloom and fruit set of pecan from leaf and fruit removal. HortScience 7:131-132.

Sparks, D., W. Reid, I. Yates, M.W. Smith, and T.G. Stevenson. 1995. Fruiting stress induces shuck decline and premature germination in pecan. J. Amer. Soc. Hort. Sci. 120:43-53.

von Broembsen, S., P. Mulder, and B.D. McCraw. 1997. Pecan insect and disease control. Okla. Coop. Ext. Ser. CR-6209.

Wood, B.W. 1989. Pecan production responds to root carbohydrates and rootstock. J. Amer. Soc. Hort. Sci. 114:223-228.

Wood, B.W. 1995. Relationship of reproductive and vegetative characteristics of pecan to previous-season fruit development and postripening foliation period. J. Amer. Soc. Hort. Sci. 120:635-642

Wood, B.W. 2001. Atypical symptoms of cold damage to pecan. HortScience 36:298-301.

Wood, B.W., W.L. Tedders, and J.D. Dutcher. 1987. Energy drain by three pecan aphid species and their influence on in-shell pecan production. Environ. Entomol. 16:1045-1056.

Worley, R.E. 1979a. Pecan yield, quality, nutlet set, and spring growth as a response of time of fall defoliation. J. Amer. Soc. Hort. Sci. 104:192-194.

Worley, R.E. 1979b. Fall defoliation date and seasonal carbohydrate concentration of pecan wood tissue. J. Amer. Soc. Hort. Sci. 104:195-199. 